\title{
Leukaemia in benzene workers: a retrospective cohort study
}

\author{
S-N YIN, ${ }^{1}$ G-L LI, ${ }^{1}$ F-D TAIN, ${ }^{1}$ Z-I FU, ${ }^{1}$ C JIN, ${ }^{1}$ Y-J CHEN, ${ }^{2}$ S-J LUO, ${ }^{3}$ P-Z YE, ${ }^{4}$ \\ J-Z ZHANG ${ }^{5}$ G-C WANG ${ }^{6}$ X-C ZHANG, ${ }^{7}$ H-N WU, ${ }^{8}$ Q-C ZHONG ${ }^{9}$
}

From the Institute of Health, ${ }^{1}$ Chinese Academy of Preventive Medicine, Beijing, Stations for Health and Prevention of Infection of Shanghai, ${ }^{2}$ Sichuan, ${ }^{3}$ Tianjin, ${ }^{6}$ and Nanchang, ${ }^{8}$ and Institutes for Prevention and Treatment of Occupational Disease in Heilongjiang, ${ }^{4}$ Shenyang, ${ }^{5}$ Helan, ${ }^{7}$ and Guangzhou, ${ }^{9}$ China

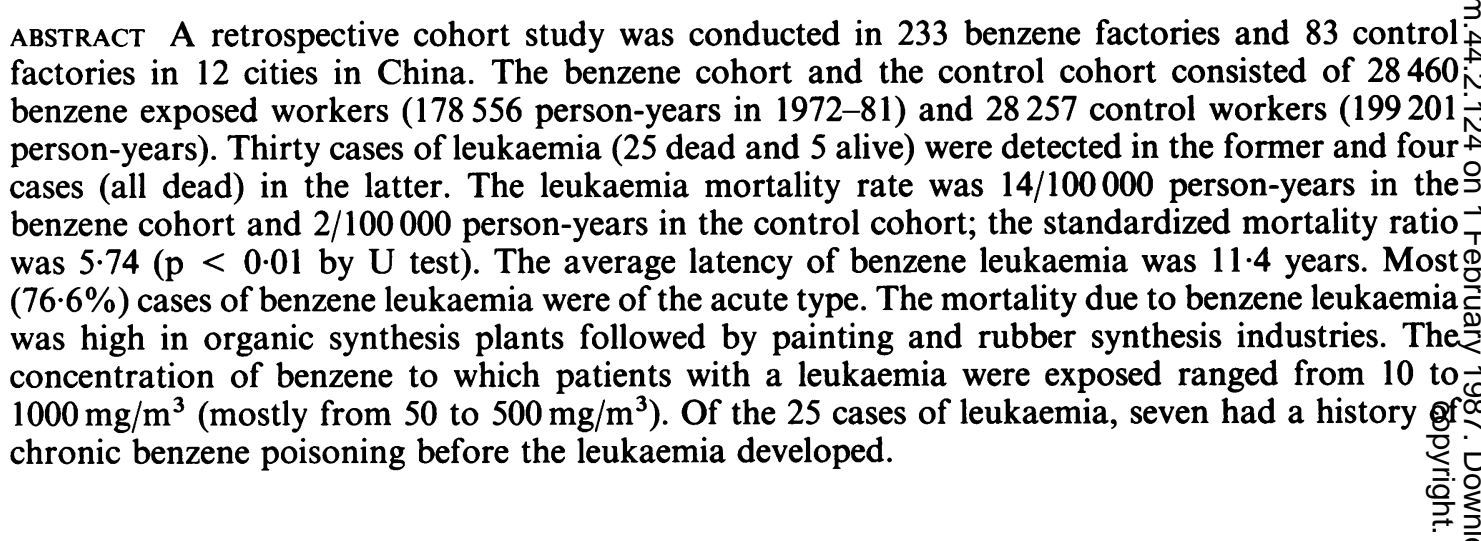

In addition to its presence in the general environment as a pollutant benzene is still used in various industries and in China some 500000 workers are exposed to benzene or a benzene containing mixture (SN Yin et al, reported at scientific committee on maximum permissible limits meeting, London, 1983). The aetiological relation between exposure to benzene and leukaemia has been reported by several authors including Vigliani and Saita, ${ }^{1}$ Ishimaru et al, ${ }^{2}$ Aksoy, ${ }^{3}$ and Rinsky et al. ${ }^{4}$ Whereas the leukaemogenic property of benzene in man has been well established, ${ }^{5}$ the epidemiological data are still considered insufficient and, especially, there has been no epidemiological report on benzene leukaemia in China. To study the causal relation between benzene and leukaemia a further retrospective cohort study was undertaken in 1982-3. The present paper reports the major findings of the study. The relation of other malignancies to exposure to benzene will be described in a separate report. ${ }^{6}$

\section{Materials and methods}

The study was conducted in the cities of Shanghai, Accepted 13 May 1986
Tianjin, Chengdu, Chongqing, Haerbin, Shenyang, ٌّ Jinzhou, Zhengzhou, Luoyang, Guangzhou, Nan- $\stackrel{\mathbb{Q}}{\mathcal{Q}}$ chang, and Kaifeng, China, in 1982-3. The members $\Rightarrow$ of the benzene group were selected from 233 painting, $\frac{0}{3}$ shoe-making, rubber synthesis, leather, and adhesive and organic synthesis factories in the 12 cities cited. The subjects had worked in those factories for at least half a year between 1 January 1972 and 31 December $\Phi$ 1981. Those in the control cohort were from 83? machine production, textile, and cloth factories in $\frac{5}{3}$ which there were no known exposures to benzene or other occupational carcinogens. The sex and age distribution in the control group were similar to that of the benzene group. The controls had also worked in 9 the same cities for at least half a year during the same $>$ period. The drop out rate was $0.8 \%$ in the benzene cohort and $1.3 \%$ in the control cohort. Thus the ben- $N$ zene cohort consisted of 28460 workers (15643 men, 12817 women) and the control cohort of 28257 sub-O jects (16621 men, 12336 women). Both cohorts were followed up from 1972 to 1981 so that $178556^{\circ}$ person-years were obtained for the benzene cohorto and 199201 the control cohort.

Items investigated included the occupational his- $\stackrel{?}{+}$ tory of the individuals, a history of benzene poisoning 
Table 1 Mortality and relative risk of leukaemia

\begin{tabular}{|c|c|c|c|c|c|c|c|c|}
\hline \multirow[b]{2}{*}{ Sex } & \multicolumn{3}{|l|}{ Benzene } & \multicolumn{5}{|l|}{ Controls } \\
\hline & Person-years & Death & Mortality & Person-years & Death & Mortality & $R R^{*}$ & $p$ \\
\hline $\begin{array}{l}\text { Men } \\
\text { Women }\end{array}$ & $\begin{array}{r}100025 \\
78531\end{array}$ & $\begin{array}{r}17 \\
8\end{array}$ & $\begin{array}{r}7 \cdot 00 \\
10 \cdot 19\end{array}$ & $\begin{array}{r}122268 \cdot 5 \\
77932.5\end{array}$ & $\begin{array}{l}3 \\
1\end{array}$ & $\begin{array}{l}2 \cdot 47 \\
1 \cdot 28\end{array}$ & $\begin{array}{l}6 \cdot 88 \\
7 \cdot 24\end{array}$ & $\begin{array}{l}<0.01 \\
<0.05\end{array}$ \\
\hline Total & 178556 & 25 & $14 \cdot 00$ & $199201 \cdot 0$ & 4 & $2 \cdot 01$ & 6.97 & $<0.01$ \\
\hline
\end{tabular}

* RR = Relative risk defined as the ratio of mortality $B$ to mortality $C$.

Table 2 Standardised mortality ratio (observed/expected) for benzene leukaemia

\begin{tabular}{|c|c|c|c|c|c|}
\hline \multirow[b]{2}{*}{ Sex } & \multicolumn{5}{|l|}{ Deaths } \\
\hline & Observed & Expected & $S M R$ & $U$ & $p$ \\
\hline $\begin{array}{l}\text { Men } \\
\text { Women }\end{array}$ & $\begin{array}{r}17 \\
8\end{array}$ & $\begin{array}{l}3.392 \\
0.964\end{array}$ & $\begin{array}{l}5.01 \\
8.30\end{array}$ & $\begin{array}{l}3 \cdot 30 \\
2 \cdot 49\end{array}$ & $\begin{array}{l}<0.01 \\
<0.05\end{array}$ \\
\hline Total & 25 & $4 \cdot 356$ & $5 \cdot 74$ & $4 \cdot 13$ & $<0.01$ \\
\hline
\end{tabular}

Table 3 Mortality rate of leukaemia in various industries

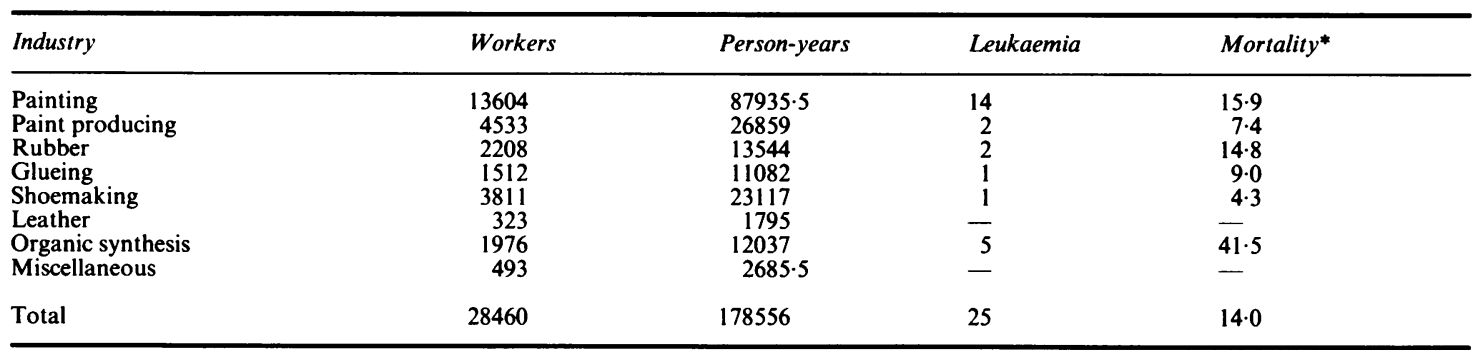

${ }^{*}$ Mortality rate: unit, $1 / 100000$ person-years.

and other specific disease, death certificates (for all known deaths), working conditions, and atmospheric benzene concentrations in the workplace; this information was collected from factory records. Benzene concentrations were determined by means of grab samples followed in the main by gas chromatographic analyses. The cases of leukaemia, aplastic anaemia, and benzene poisoning were obtained from hospital records; the diagnosis of benzene poisoning was established based on China national criteria for diagnosis of benzene poisoning ${ }^{7}$ including occupational history, a peripheral leukocyte count of less than $\mathbf{4 0 0 0}$ cells $/ \mathrm{mm}^{3}$, and symptoms or signs in the central nervous system. The vital status was followed up until 31 December 1981. The standardized mortality ratio (SMR) was calculated with reference to the deaths in the control cohort.

\section{Results}

MORTALITY AND RELATIVE RISK OF LEUKAEMIA In total, 30 cases of benzene leukaemia were found in the benzene cohort, of whom 25 had died and five were alive in 1972-81; four cases of leukaemia were found in the control cohort (all dead). The mortality rate of leukaemia was 14/100 000 person-years in the benzene cohort and 2.01/100 000 person-years in the control cohort. The relative risk of leukaemia for the benzene workers was 6.97 and was significantly high both in men and women (table 1).

As 25 cases of benzene leukaemia (excluding five live cases) were observed compared with $4 \cdot 3$ expected, the SMR was 5.01 for men, 8.30 for women, or 5.74 for both (table 2). When the mortality due to benzene leukaemia was compared in the various industries, the rate was highest in organic synthesis factories followed by the painting and rubber synthesis industries (table 3).

AGE AND LATENCY IN CASES OF LEUKAEMIA The ages of the patients with leukaemia in the benzene cohort ranged from 24 to 62 with a mean of 39.7 years (38.1 for men, 36.0 for women). The mean age of the patients with leukaemia was lower in the ben- 


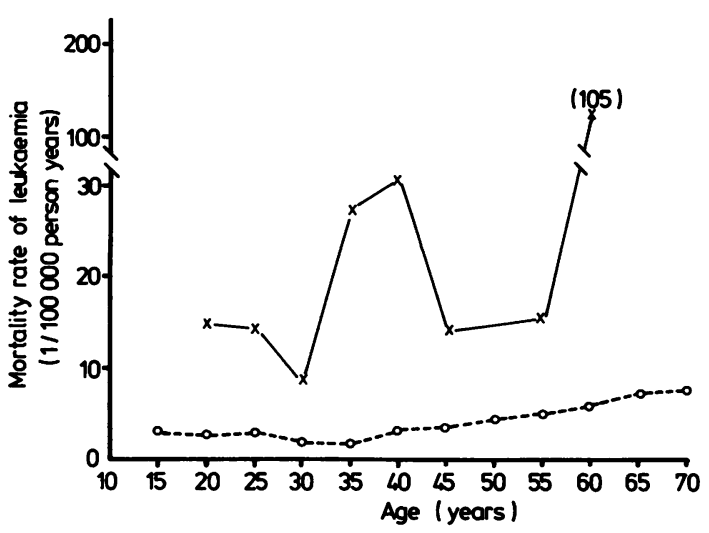

Fig 1 Leukaemia mortality rate in male workers at various ages. Solid line indicates mortality rate among workers in benzene cohort. Broken line indicates values among male adults in big cities in China (data obtained from the National Control Office of the Ministry of Health, 1979).

zene cohort (38.1 years when both sexes combined) than in the control cohort ( 46.7 years). The mortality for leukaemia increased in the age range $35-45$ in the benzene cohort (fig 1). The average age of the workers when exposure began was 27.8 years. Figure 2 shows the relation between the start of exposure and the time of diagnosis (the latency period). Among the 30 cases of leukaemia in the benzene cohort the average latency was 11.4 years (minimum 0.8 , maximum 49.5 years, respectively). The cumulative mortality of leukaemia was in proportion to the duration of exposure up to 20 years and then levelled off (fig 3 ), as

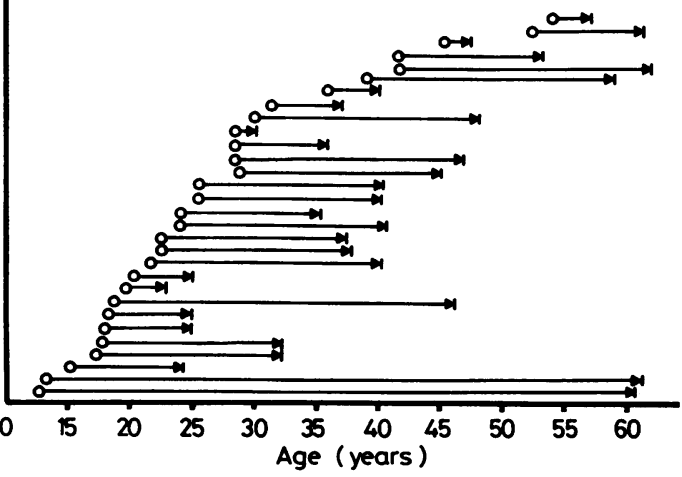

Fig 2 Age at start of exposure, of diagnosis of leukaemia, and latency of 30 cases of leukaemia. $O$ indicates ages of the initiation of the exposure and ages at which diagnosis of leukaemia was established. Connecting lines show period of latency.

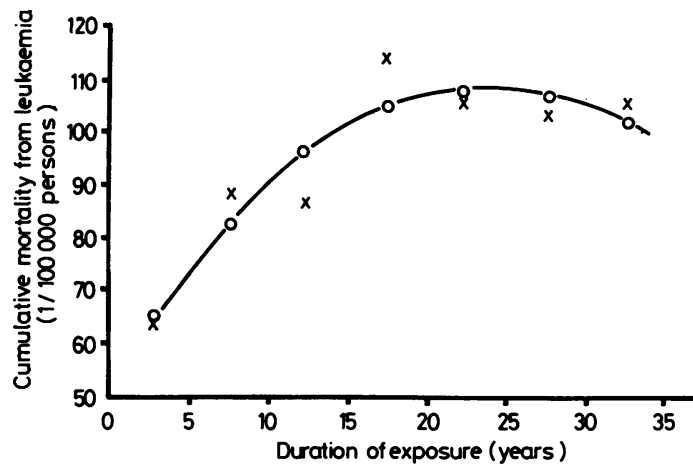

Fig 3 Relation of cumulative mortality of leukaemia with duration of exposure. Crosses indicate cumulative mortality of leukaemia observed. Open circles indicate value estimated by an orthogonal polynomical curve of

$$
y=55.56+4.4471 x-0.09248 x^{2}
$$

where $y$ is cumulative mortality $\left(1 / 10^{5}\right.$ persons $)$ and $x$ is duration of benzene exposure (years).

was well described by an orthogonal polynominal $\vec{T}$ curve of the form:

$$
y=55.56+4.4471 x-0.09248 x^{2}
$$

where $y$ is the cumulative mortality $\left(1 / 10^{5}\right.$ persons $)$ and $\mathrm{x}$ is the duration of benzene exposure (years).

Table 4 Benzene concentration in workplaces where cases

\begin{tabular}{|c|c|c|}
\hline No of cases & Industry & $\begin{array}{l}\text { Benzene concentration } \\
\left(\mathrm{mg} / \mathrm{m}^{3}\right)\end{array}$ \\
\hline $\begin{array}{r}2 \\
3 \\
4 \\
5 \\
6 \\
7 \\
8 \\
9 \\
10 \\
11 \\
12 \\
13 \\
14 \\
15 \\
16 \\
17 \\
18 \\
19 \\
20 \\
21 \\
22 \\
23 \\
24 \\
25 \\
26 \\
27 \\
28 \\
29 \\
30\end{array}$ & $\begin{array}{l}\text { Laboratory in rubber } \\
\text { factory } \\
\text { Chemical reagent } \\
\text { Paint } \\
\text { Glue } \\
\text { Paint } \\
\text { Paint } \\
\text { Paint } \\
\text { Paint } \\
\text { Paint } \\
\text { Paint } \\
\text { Paint } \\
\text { Benzene refined } \\
\text { Chemical analysis } \\
\text { Paint } \\
\text { Cleaning } \\
\text { Organic synthesis } \\
\text { Paint } \\
\text { Shoemaking } \\
\text { Paint } \\
\text { Paint } \\
\text { Paint } \\
\text { Paint } \\
\text { Paint } \\
\text { Paint producing } \\
\text { Paint } \\
\text { Paint } \\
\text { Organic synthesis } \\
\text { Paint } \\
\text { Rubber } \\
\text { Paint producing }\end{array}$ & $\begin{array}{c}136 \cdot 2(99 \cdot 3-173 \cdot 1) \\
253 \cdot 9(20-440 \cdot 2) \\
50 \cdot 2(0-220) \\
100(30-150) \\
190 \cdot 6(5-1200) \\
26 \cdot 5(0-250) \\
15 \cdot 5(3-39 \cdot 4) \\
15(10-20) \\
203 \cdot 1(25-500) \\
239 \cdot 3(0-4736) \\
30 \cdot 2(0-341 \cdot 3) \\
474 \cdot 2(0-4024) \\
87 \cdot 8(5 \cdot 3-170 \cdot 2) \\
1104 \cdot 7(3 \cdot 5-3826)^{*} \\
6 \cdot 5(1 \cdot 6-11 \cdot 4) \\
15 \cdot 4(1 \cdot 4-50 \cdot 0) \\
243 \cdot 6(0-618) \\
13 \cdot 3 * \\
190 \cdot 8(42-453) \\
468 \cdot 1(13 \cdot 7-5508) \\
301(250-352) \\
118 \cdot 9(31 \cdot 3-206 \cdot 4) \\
575 \cdot 2(2 \cdot 2-6102) \\
21 \cdot 4(0 \cdot 7-80 \cdot 1) \\
96 \cdot 8 \\
68 \cdot 2(54 \cdot 7-138 \cdot 8) \\
8 \cdot 3(6 \cdot 5-10)^{*} \\
37 \cdot 1(2 \cdot 1-94 \cdot 1) \\
86 \cdot 4(4 \cdot 9-116 \cdot 2) \\
159 \cdot 5(10-733)\end{array}$ \\
\hline
\end{tabular}
of leukaemia were observed

*Single measurement. 
BENZENE CONCENTRATION IN THE WORKPLACES WHERE CASES OF LEUKAEMIA WERE OBSERVED

Table 4 shows the benzene concentrations in the workplaces where the 30 patients with leukaemia had worked. The mean concentrations varied in a wide range of 10 to $1000 \mathrm{mg} / \mathrm{m}^{3}$ but were mostly in the range $50-500 \mathrm{mg} / \mathrm{m}^{3}$.

\section{LEUKAEMIA MORTALITY AMONG CASES OF BENZENE POISONING}

In the benzene cohort 196 cases of chronic benzene poisoning and aplastic anaemia were found; seven of the 25 patients with leukaemia had a history of chronic benzene poisoning (for criteria of the diagnosis, see materials and methods) or aplastic anaemia, or both, before being diagnosed as having a leukaemia. The leukaemia mortality among benzene poisoning cases was $700 \cdot 70 / 100000$ person-years, and was 49 times higher than that in the benzene workers (14/100000).

\section{TYPES OF BENZENE LEUKAEMIA}

Among the 30 cases of benzene leukaemia, 23 $(76 \cdot 7 \%)$ were acute and seven $(23 \cdot 3 \%)$ chronic. The cases of acute leukaemia comprised 13 myelogenous, four monocytic, two myelocytic-monocytic, one erythromyelocytic, and three lymphocytic leukaemia. Chronic leukaemia included five with myelogenous leukaemia, one lymphosarcomatous leukaemia, and one unidentified case.

\section{Discussion}

Benzene is a well established human carcinogen. ${ }^{5}$ In addition, Goldstein $e t$ al and Maltoni et al have presented data suggesting that benzene may cause leukaemia in rodents. ${ }^{89}$ About 289 benzene exposure related cases of leukaemia have been reported in Italy, China, France, Japan, the Soviet Union, Turkey, and the United States. ${ }^{10}$ In the past 20 years several epidemiological studies have shown that long term occupational exposure to benzene at high concentration is associated with the occurrence of various blood dyscasias including leukaemia. ${ }^{11}$ For example, Aksoy reported 34 cases of leukaemia among shoemakers in Istanbul in 1967-753; the incidence of leukaemia was $13 / 100000$ in shoemakers by contrast with 6/100000 in the general population. Rinksy et al investigated two pliofilm manufacturing plants and found that the SMR for benzene leukaemia was $560 .^{4}$ In a recent study of a chemical plant where benzene had been used as a material for organic synthesis DeCouflé et al observed four deaths due to lymphoreticular cancers (2 leukaemia, 1 leukaemia multiple myeloma, 1 multiple myeloma) in a 30 year follow up study of 259 male workers by contrast with $1 \cdot 1$ expected deaths ${ }^{12}$; no quantitative data on benzene exposure were available, however. Arp et al reviewed the history of solvent use, raw materials specification, and the job description of 15 cases of lymphatic leukaemia in a rubber industry and comparing them with 30 matched controls found that patients with leukaemia had spent more time in jobs with potential exposure to coal tar based benzene and xylene. ${ }^{13}$ Tsai et al by contrast found no deaths from leukaemia in a study of 454 workers who had been employed in a refinery from 1952 to 1978 and exposed to benzene either at $0.14 \mathrm{ppm}$ (median; refinery workers) or $0.53 \mathrm{ppm}$ (median; workers in benzene related units). ${ }^{14}$ In the present retrospective cohort study of workers exposed to benzene the mortality from leukaemia was higher than that in the control cohort (SMR 574 for men + women; 501 for men, 830 for women) being in line with the findings by Rinsky et al. ${ }^{4}$

The mean latency period of benzene leukaemia was 11.4 years (range 0.8 to 49.5 ) (fig 2). It is similar to the observation by Vigliani and Saita of $1-46$ years, ${ }^{1}$ Goguel $e t$ al of 1-20 years, ${ }^{15}$ and Infante $e t$ al of 2-21 years. ${ }^{16}$ The average age of initial exposure to benzene among the cases of leukaemia was 27.8 years. When 11.4 years of latency is added the sum is about 39 years, which falls in the age range (35-45) of peak leukaemia mortality (fig 1). This may explain why the leukaemia mortality was highest in those aged 35-45.

With regard to the benzene concentration to which patients with leukaemia were exposed, some authors have estimated that it ranged from 200 to $600 \mathrm{ppm}$ without exact details. ${ }^{1718}$ Recently, Rinsky et al reported that their patients were exposed to benzene at $16-100 \mathrm{ppm}$, only slightly over the current OSHA standard of $10 \mathrm{ppm}^{4}$ In the present study the benzene concentrations in the workplaces where the patients had worked were reported to be $10-100 \mathrm{mg} / \mathrm{m}^{3}$ (about 3-300 ppm) and mostly in the range $50-500 \mathrm{mg} / \mathrm{m}^{3}$ (about $16-160 \mathrm{ppm}$ ), the levels being similar to the observation by Rinsky et al. ${ }^{4}$ There remains a possibility that leukaemia may develop among the less heavily exposed workers. In fact in the present study three cases of leukaemia were associated with a benzene concentration of $10 \mathrm{mg} / \mathrm{m}^{3}$ in the workplace air even though the occupational hygiene data were not adequate for quantitative estimation of exposure intensity. In this connection Infante et $a^{20}$ cited the fact that Kligerman et al (paper presented at the international symposium on sister chromatid exchange, Brookhaven, 1984) had detected a significant increase in sister chromatid exchanges (SCE) in peripheral lymphocytes and in the micronuclei in bone marrow erythrocytes of mice exposed 
to benzene at $10 \mathrm{ppm}$ for only 10 hours. By contrast, Sarto et al found no significant increase in SCE in the blood of the workers exposed to benzene in the range of 0.2 to $12.4 \mathrm{pm}$, although changes in chromosomal aberration were significant. ${ }^{20}$ Thus this possibility apparently deserves further attention.

It should be noted that seven of the 25 patients had had a history of chronic benzene poisoning such as leukopaenia or aplastic anaemia, or both, before the leukaemia developed. The leukaemia mortality was as high as $700 \cdot 70 / 100000$ person-years in cases of chronic benzene poisoning. Aksoy also observed the development of 13 cases of leukaemia in 51 pancytopaenic patients with benzene exposure. ${ }^{21}$ Thus a close relation between leukaemia and benzene poisoning should be considered. Accordingly, it may be deduced that the prevention of benzene poisoning, is the best way to prevent benzene leukaemia. The way to monitor preleukaemic changes in benzene poisoning, however, remains to be established.

This investigation was supported and organised by the Ministry of Public Health of the Government of China. We are grateful to Professor M Ikeda, Department of Environmental Health, Tohoku University School of Medicine, Sendai, Japan, for his interest in this work and his critical review of the manuscript. We thank S-X Yand, Y-Z Wang, W-Y Zhang, T-R Dai, X-J Chao, F-Y Jie, Y-H Huan, D-Y Ding, Z-L Jiang, C-Q Wu, J-S Zhou, and J-F Mu for participating in this study.

Requests for reprints to: Dr Songnian Yin, Institute of Health, Chinese Academy of Preventive Medicine, 29 Nan Wei Road, Beijing, China.

\section{References}

1 Vigliani EC, Saita G. Benzene and leukaemia. $N$ Engl J Med 1964;271:872-6.

2 Ishimaru T, Okada H, Tomiyasu T, Tsuchimoto T, Hoshino T. Tchimaru M. Occupational factors in the epidemiology of leukaemia in Hiroshima and Nagasaki. Am $J$ Epidemiol 1971;93:157-65.
3 Aksoy M. Different types of malignancies due to occupationaP exposure to benzene. A review of recent observation in Turkes Environ Res 1980;23:181-90.

4 Rinsky RA, Young RJ, Smith AB. Leukaemia in benzene workers. Am J Ind Med 1981;2:217-45.

5 International Agency for Research on Cancer. Monographs on the evaluation of the carcinogenic risk of chemicals to human? Vol 29. Benzene. Lyon: IARC, 1982:93-148.

6 Yin S-N, Li G-L, Tain F-D, et al. Epidemiological study o relationship between benzene and leukaemia and other cancer Chinese Journal of Industry Hygiene Occupational Diseas@ (in press).

7 China national criteria for diagnosis of benzene poisoning. Beijing: Ministry of Public Health of the Government of China, 19740 (In Chinese.)

8 Goldstein BD, Snyder CA, Laskin S, Bromberg I, Albert RE Nelson N. Myelogenous leukaemia in rodents inhaling benzene. Toxicol Lett 1982;13:169-73.

9 Maltoni C, Conti B, Cotti G, et al. Experimental studies on benzene carcinogenicity at the Bologna Institute of Oncology Am J Ind Med 1985;7:415-46.

10 Yin S-N, Li G-L. Advance of studies on benzene leukaemiaĩ Communication of Medical Research 1981;11:5-7. (In Chinese.

11 Van Raalte HGS, Grasso P. Hematological, myelotoxic clastoxic, carcinogenic and leukemogenic effects of benzeneo Regulatory Toxicology and Pharmacology 1982;2:153-76.

12 Decoufle P, Blattner WA, Blair A. Mortality among chemicaT workers exposed to benzene and other agents. Environ Re 1983;30:16-25.

13 Arp EW, Wolf PW, Checkoway H. Lymphocytic leukaemia an exposures to benzene and other solvents in the rubber industry. J Occup Med 1983;25:598-602.

14 Tsai SP, Wen CP, Weiss NS, Wong O, McClellan WA, Gibson RL. Retrospective surveillance studies of workers in benzenç areas of refineries. J Occup Med 1983;25:685-92.

15 Goguel A, Gavigneaux A, Bernard J. Les leucemics benzeniqueg de la region Parisienne entre 1950 et 1965 (etude de्Cs observations). Nouv Rev Fr Hematol 1967;7:465-80.

16 Infante PF, Rinsky PA, Wagoner JK, Young RJ. Leukemia if benzene workers. Lancet 1977;ii:76-8.

17 Aksoy M, Dincol K, Erdem S, Dincol G. Acute leukemia due t $\$$ chronic exposure to benzene. Am J Med 1972;52:160-6.

18 Vigliani EC. Leukaemia associated with benzene exposure. An NY Acad Sci 1976;271:143-51.

19 Infante PF, White MC. Projections of leukaemia risk associate with occupational exposure to benzene. Am J Ind Med 1985;7:403-13.

20 Sarto F, Cominato I, Pinton AM, et al. A cytogenetic study of workers exposed to low concentrations of benzene. Carcinos genesis 1984;5:827-32.

21 Aksoy M. Malignancies due to occupational exposure t benzene. Am J Ind Med 1985;7:395-402. 